\title{
An Unexpected Cause of Catastrophic Bleeding: A Case Report
}

\author{
Majid H. Alabbood \\ Medicine, Alzahraa College of Medicine, University of Basrah, Basrah, Iraq
}

\section{Keywords}

Hypothyroidism · von Willebrand syndrome · Bleeding ·

Thyroid hormones · Endocrinology

\begin{abstract}
Profound hypothyroidism has been linked to mild bleeding diathesis such as easy bruising and menorrhagia. Bleeding tendency depends on the severity of hypothyroidism. Those with moderate disease are prone to thrombotic events, while those with profound hypothyroidism are prone to bleeding. This paper reports a case of severe intraoperative bleeding during elective rhinoplasty in a patient with missed profound hypothyroidism. The clinical and laboratory findings are presented with a review of the literature. A 43-yearold female was admitted for an elective rhinoplasty. In the theater, the patient developed massive bleeding at the beginning of surgery. On the next day, the patient was discharged home for further assessment with a massive bruise all over her face. Upon history taking, the patient denied any drug abuse or previous bleeding episode or family history of bleeding disorder. Surprisingly, a transverse scar was noted at the lower part of the neck. The patient admitted that she had thyroidectomy done 2 years ago, and she was kept on
\end{abstract}

karger@karger.com www.karger.com/dde

Karger!"

BOPEN ACCESS
(C) 2020 The Author(s)

Published by S. Karger AG, Basel

This article is licensed under the Creative Commons AttributionNonCommercial-NoDerivatives 4.0 International License (CC BYNC-ND) (http://www.karger.com/Services/OpenAccessLicense) Usage and distribution for commercial purposes as well as any distribution of modified material requires written permission. thyroxine replacement and stopped it by herself 18 months ago. Thyroid-stimulating hormone (TSH) was $70 \mathrm{mU} / \mathrm{L}$, and von Willebrand factor antigen/ristocetin cofactor was normal. A diagnosis of acquired von Willebrand syndrome type 1 was made. The patient was kept on thyroxine $150 \mu \mathrm{g} /$ day. Six weeks later, TSH was $0.8 \mathrm{mU} / \mathrm{L}$, and all bleeding parameters were corrected. A careful history taking and general examination looking for hypothyroidism is crucial in the preoperative assessment. It might be prudent to include thyroid function test in the routine preoperative investigation of all patients.

(c) 2020 The Author(s)
Published by S. Karger AG, Basel

\section{Introduction}

Hypothyroidism is a common endocrine disorder and it has a predilection to females [1]. If untreated, it will lead to serious adverse health outcomes such as cardiovascular diseases [2]. Profound hypothyroidism has been linked to mild bleeding diathesis such as easy bruising and menorrhagia [3]. Although the exact mechanism is unknown [1], alteration in the level of plasma von Willebrand factor (vWF), fibrinogen, d-Dimer, and plasminogen activator inhibitor 
type 1 plasminogen activator inhibitor type 1 as well as low platelet adhesiveness has been documented in previous studies $[1,2,4,5]$. Furthermore, bleeding tendency depends on the severity of hypothyroidism. Those with moderate disease are prone to thrombotic events, while those with profound hypothyroidism are prone to bleeding [1].

\section{Case Presentation}

A 43-year-old female, married and nonsmoker, was admitted to Alsader Teaching Hospital, Basrah, Iraq, for an elective rhinoplasty. Routine preoperative general investigations were normal. In the theater, the patient developed massive bleeding after a small incision in the nose at the beginning of surgery. The bleeding was so severe that it resulted in massive blood loss. It was difficult to control the bleeding despite all measures, and the patient was at risk of impending shock. Four pints of blood were given, and after $8 \mathrm{~h}$, the patient's condition was stabilized, and she could be referred to the ward. On the next day, the patient was discharged home with a massive bruise all over her face. Then, she was referred for assessment for any bleeding tendency. Upon history taking, the patient denied any drug abuse, previous bleeding episode, or family history of bleeding disorder. Upon general examination, she was alert, not pale, with blood pressure $117 / 90 \mathrm{~mm} \mathrm{Hg}$ and pulse rate $72 \mathrm{bpm}$. Her weight was $59 \mathrm{~kg}$, and her height was $159 \mathrm{~cm}$. Surprisingly, a transverse scar was noted at the lower part of the neck. The patient admitted that she had thyroidectomy done 2 years ago for euthyroid goiter, and she was kept on thyroxine replacement and stopped it by herself 18 months ago. The surgery was uneventful except for postoperative hypocalcemia for which she was kept on calcium tablets for 2 years. The other part of the examination was unremarkable. Initial laboratory blood tests are shown in Table 1.

The patient attributed her noncompliance with thyroxine therapy to poor memory and forgetfulness. Thyroxine tablets were started immediately at a dose of $100 \mu \mathrm{g} /$ day and were titrated to $150 \mu \mathrm{g}$ daily after 2 weeks. The patient was instructed to take thyroxine in the early morning on an empty stomach.

At the follow-up visit 6 weeks later, the patient felt better and reported improved activity. The facial bruise had disappeared. Blood tests on the second visit showed an improvement in thyroidstimulating hormone (TSH; $0.8 \mathrm{mU} / \mathrm{L})$, free T4 (1.7 ng/dL), bleeding time (BT, $2 \mathrm{~min}$ ), clotting time (3 min), factor VIII concentration (FVIIIc) (120\%), vWF antigen (Ag, 145\%), and vWF/ristocetin cofactor (RCF) ratio (141\%). Therefore, the dose of thyroxine was reduced to $125 \mu \mathrm{g}$ daily, and the patient was referred back to the plastic surgeon to perform the postponed rhinoplasty.

\section{Discussion and Conclusion}

Normal vWF antigen/ristocetin cofactor (vWF Ag/ $\mathrm{RCF}$ ) ratio indicates acquired vWS (AvWS) type 1, as in the index case [6]. AvWS has been described in association with monoclonal gammopathies, lymphoid, myelo-
Table 1. Blood test results on the first visit

\begin{tabular}{lrc}
\hline Blood test & Result & Reference range \\
\hline TSH, mU/L & 70 & $0.45-4.12$ \\
FT3, pg/dL & 140 & $260-480$ \\
FT4, ng/dL & 0.5 & $0.7-1.8$ \\
Hb, g/dL & 12.4 & $12.0-15.5$ \\
WBC, $\times 10^{9} / \mathrm{L}$ & 7 & $4-11$ \\
Platelet, $/ \mu \mathrm{L}$ & 200,000 & $150,000-450,000$ \\
aPTT, s & 39 & $30-40$ \\
VIIIc, \% & 44 & $50-150$ \\
vWF Ag, IU/dL & 45 & $50-150$ \\
BT, min & 11 & $2-9$ \\
vWF Ag/RCF, \% & 95 & $60-160$ \\
\hline
\end{tabular}

VIIIc, factor VIII concentration; aPTT, activated partial thromboplastin time; BT, bleeding time; FT3, free T3; FT4, free T4; Hb, hemoglobin; RCF, ristocetin cofactor; TSH, thyroid- stimulating hormone; vWF Ag, von Willebrand factor antigen; WBC, white blood cells.

proliferative, autoimmune, and metabolic or hormonal disorders [6]. Severe hypothyroidism (defined as TSH $>50$ $\mathrm{mU} / \mathrm{L}$ ) has been linked to bleeding tendency [1]. In one study conducted on 41 women with moderate and severe hypothyroidism, significantly lower levels of alpha-2-antiplasmin activities, tissue plasminogen activator, and plasminogen activator inhibitor type $1 \mathrm{Ag}$ were documented in the severe-hypothyroidism group [1]. Low FVIIIc may be due to acquired hemophilia secondary to underlying autoimmune disease such as Hashimoto's thyroiditis. However, this condition is rare, and according to previously published data, the most common cause of bleeding tendency associated with hypothyroidism is acquired von Willebrand disease type I [7]. Furthermore, prolonged BT with normal activated partial thromboplastin time points to vWS rather than acquired hemophilia. Additionally, the bleeding diathesis was corrected by thyroxine therapy alone. Unfortunately, no inhibitory antibody test has been done to exclude the presence of inhibitory antibodies against FVIII, which makes acquired hemophilia a possible, though rare diagnosis. Lastly, the low FVIIIc may be attributed to generalized diminution of protein synthesis in profound hypothyroidism, and it has been reported in several case reports [6].

The importance of the index case from an educational point of view lies first in the fact that severe hypothyroidism might be missed and consequently results in severe bleeding intraoperatively. In the preoperative history taking, the index case forgot to tell about her previous thyroidectomy. Second, patients with severe hypothyroidism 
might not have the classical signs and symptoms of hypothyroidism and might present an unprecedented bleeding episode for the first time. The initial examination of the index case has not revealed any of the classical signs of severe hypothyroidism, such as apathy, dry skin, hair loss, slow speech, and eye lid edema. Third, history alone might not be enough to exclude iatrogenic hypothyroidism, as those patients usually have memory problems secondary to their hypothyroxinemia, and hence neck examination looking for any scar of previous thyroidectomy is important. Fourth, almost all bleeding episodes described in previous case reports were mild and mucocutaneous [4, 6-8]. In the index case, the bleeding was massive, difficult to control, and resulted from a surgeon's scalpel. The correction of vWF Ag and BT after thyroxine therapy was the ultimate proof of the diagnosis of AvWS in the index case.

In conclusion, a careful history taking and general examination looking for hypothyroidism is crucial in the preoperative assessment. Those with proved diagnosis of hypothyroidism or thyroidectomy should have their TSH corrected prior to surgery. It might be prudent to include thyroid function test in the routine preoperative investigation of all patients.

\section{Acknowledgement}

The author would like to thank the plastic surgery team at Alsader Teaching Hospital for referring the case for assessment, and Haider Alrubaey Lab for performing the blood tests.

\section{Statement of Ethics}

This report complies with the guidelines for human studies and was conducted ethically in accordance with the World Medical Association Declaration of Helsinki. An informed consent was taken from the patient to publish this report.

\section{Disclosure Statement}

The author has no conflicts of interest to declare.

\section{Funding Sources}

There are no funding sources to declare.

\section{References}

1 Chadarevian R, Bruckert E, Leenhardt L, Giral P, Ankri A, Turpin G. Components of the fibrinolytic system are differently altered in moderate and severe hypothyroidism. J Clin Endocrinol Metab. 2001 Feb;86(2):732-7.

2 Rennie JA, Bewsher PD, Murchison LE, Ogston D. Coagulation and fibrinolysis in thyroid disease. Acta Haematol. 1978;59(3):171-7.

3 Ford HC, Carter JM. Haemostasis in hypothyroidism. Postgrad Med J. 1990 Apr; 66(774):280-4.
4 Edson JR, Fecher DR, Doe RP. Low platelet adhesiveness and other hemostatic abnormalities in hypothyroidism. Ann Intern Med. 1975 Mar;82(3):342-6.

5 Myrup B, Bregengård C, Faber J. Primary haemostasis in thyroid disease. J Intern Med. 1995 Jul;238(1):59-63.

6 Michiels JJ, Schroyens W, Berneman Z, van der Planken M. Acquired von Willebrand syndrome type 1 in hypothyroidism: reversal after treatment with thyroxine. Clin Appl Thromb Hemost. 2001 Apr;7(2):113-5.
7 Manfredi E, van Zaane B, Gerdes VE, Brandjes DP, Squizzato A. Hypothyroidism and acquired von Willebrand's syndrome: a systematic review. Haemophilia. 2008 May;14(3): 423-33.

8 Soni S, Singh G, Yasir S, Hatipoglu B. An unusual presentation of hypothyroidism. Thyroid. 2005 Mar;15(3):289-91. 